\title{
Development of Traditional Snack Items with Fermented Quinoa
}

\author{
P. Prathyusha ${ }^{1}$, B. Anila Kumari ${ }^{*}$, K. Uma Maheswari ${ }^{1}$, \\ K. B. Suneetha Devi ${ }^{2}$ and W. Jessie Suneetha ${ }^{1}$
}

${ }^{1}$ Department of Foods and Nutrition, Professor Jayashankar Telangana State, Agricultural University, Rajendranagar, Hyderabad, 500030, Telangana, India

${ }^{2}$ Department of Agronomy, College of Agriculture, PJTS Agricultural University, Rajendranagar, Hyderabad, 500030, Telangana, India

*Corresponding author

\section{A B S T R A C T}

\section{Keywords \\ Fermented quinoa, Snacks, Namakpara, Chekkalu \\ Article Info \\ Accepted: \\ 24 October 2018 \\ Available Online: \\ 10 December 2018}

\begin{abstract}
Quinoa (Chenopodium wild) belongs to goosefoot family of "Chenopodiaceae". Quinoa is mostly useable and consumable grain in all over the world now a day because of their excellent nutritional composition. Present study aims to develop fermented quinoa incorporated snack items. Fermented quinoa flour was incorporated at $25 \%, 50 \%, 75 \%$ and $100 \%$ in snack items like namakpara and chekkalu. Incorporated snack items were organoleptically evaluated by semi trained panel members. The mean sensory scores for colour, texture and flavour of fermented quinoa incorporated namakpara were very near to control. Namakpara incorporated with $25 \%$ fermented quinoa and chekkalu incorporated with $50 \%$ were acceptable.
\end{abstract}

\section{Introduction}

Cereals and pseudocereals belong to the most important primary food due to rich in proteins, carbohydrates, amino acid composition, vitamins and minerals.

These grains mostly consumed in the form of breakfast cereals, bars and bread in developed countries (Kockova et al., 2013).

Quinoa (Chenopodium wild) is consider as a pseudocereal plants and it is cultivated all over the world because of its wonderful sustainable nature. The consumption of quinoa was helpful in reduce the blood cholesterol level, and maintains good health conditions due to its excellent nutritional composition such as dietary fiber, proteins, essential amino acids, phytochemicals, vitamins and minerals (Elget et al., 2014).

Fermentation is a food processing technique used to enhance the distinctive flavour, digestibility, nutrients and helps in reduce the antinutritional factors present in food their by availability of nutrients to the human being was increased.

This is also is desirable process for improvement of sensory quality of products by producing aroma compounds like lactic acid 
bacteria and also extends shelf life of products through the production of antimicrobial compounds (Corsetti and Settanni, 2007).

The objective of present study is to develop fermented quinoa flour incorporated traditional snack items to increase the consumption of quinoa as well as increase the nutrient density of the products. Chekkalu (A traditional snack item prepared with rice flour and spices generally consumed in south India) and namakpara were select for preparation of fermented quinoa incorporated snacks because these snacks are most popular and easy to prepare crispy snack items preferred by all age groups in south India.

\section{Materials and Methods}

\section{Procurement of raw materials}

Quinoa seeds were obtained from Department of Agronomy, College of Agriculture, PJTS Agricultural University, Rajendranagar, Hyderabad. The other ingredients were procured from local market of Hyderabad.

\section{Processing of fermented quinoa flour}

Wet milled quinoa flour was fermented by fallowing the procedure of Carciochi et al., (2016).

\section{Preparation of traditional snack items}

All the traditional snack items prepared by replacing major cereals and millet in the different proportions of $25 \%, 50 \%, 75 \%$, $100 \%$ as given in the Table 1 and 2. Snack item without incorporation of fermented quinoa flour served as control. While preparing namakpara midha (refined wheat flour) was kept constant where as in chekkalu rice flour was replaced by fermented quinoa flour. Both the snack items were prepared fallowing the traditional procedures.

\section{Sensory evaluation of products}

Sensory evaluation of fermented quinoa based south Indian breakfast items were carried out by fifteen semi-trained panel members from PGRC, PJTSAU using 9 point hedonic scale (Meilgaard et al., 1999) evaluated for attributes such as colour, texture, flavour, taste and overall acceptability. The scale were based on hedonic scale of 1 to 9 where: $1=\mathrm{I}$ dislike extremely (very bad) and $9=$ I like extremely (excellent). The samples were presented with pre-coding of three digit numbers in individual booths in sensory evaluation lab. Panellist rinsed their mouth with water after testing each sample.

\section{Statistical analysis}

The results were statistically analysed (Snedecor et al., 1983) the results were presented as mean \pm standard deviation. Difference between the variables was tested for significance by ANOVA using SAS version 9.1. To select final best acceptable combination of products the actual scores of overall acceptability given by 15 panel members were taken and box-plot diagram was drawn. Boxplot descriptive statistics are presented in Figures 2 and 4 and discussed in the results.

\section{Results and Discussion}

\section{Sensory evaluation of namakpara incorporated with fermented quinoa flour}

Mean sensory scores of namakpara incorporated with fermented quinoa flour was stated in Figure 1. Mean sensory scores of namakpara for colour QN3 (7.73 \pm 0.23$)$ had maximum mean sensory score whereas QN1 $(6.47 \pm 0.40)$ had minimum mean sensory score. Results showed that there was no significant difference $(\mathrm{p} \leq 0.05)$ between TCN and QN2 where as other were having 
significant difference. The mean sensory score of namakpara for texture were ranged from $6.47 \pm 0.40(\mathrm{QN} 1)$ to $7.53 \pm 0.32(\mathrm{QN} 3)$. QN3 sample got better score for texture than the control sample. The results showed that there was no significant difference $(\mathrm{p} \leq 0.05)$ between QN1 and QN4 as well as QN2 and $\mathrm{TCN}(\mathrm{p} \leq 0.05)$.

For taste mean sensory scores of namakpara was decreased from $7.47 \pm 0.26(\mathrm{TCN})$ to $6.67 \pm 0.21(\mathrm{QN1})$. The mean score for taste was highest for control sample (TCN). But within the fermented quinoa incorporated namakpara QN4 (7.40 \pm 0.19$)$ had highest score whereas QN2 (6.67 \pm 0.21$)$ was given lowest mean sensory score for taste. The results clearly show that there was no significant difference $(\mathrm{p} \leq 0.05)$ between TCN and QN4 as well as QN3 and QN1 $(\mathrm{p} \leq 0.05)$.
Highest mean sensory scores for flavour $(7.40 \pm 0.21)$ and overall acceptability (7.67 \pm 0.27$)$ was given to QN3. Lowest mean sensory scores for flavour was given to QN1 $(6.60 \pm 0.27)$, where as in overall acceptability QN2 scored low (7.00 \pm 0.24$)$. Results showed that there was no significant difference $(\mathrm{p} \leq 0.05)$ between $\mathrm{QN} 3$ and TCN.

To select final best acceptable combination of namakpara the actual scores of overall acceptability given by 15 panel members were taken and box-plot diagram was drawn. Boxplot descriptive statistics of namakpara are presented in Figure 2. The box plot diagram clearly shows that the median (8) and maximum (9) values of overall acceptability of control QN2, QN3, QN4 had same median value where asQN3 had equal maximum value with control which shows that QN3 equal acceptable as control.

Table.1 Ingredients used in preparation of namakpara incorporated with fermented quinoa flour

\begin{tabular}{|c|c|c|c|}
\hline Combinations & Wheat flour (g) & Midha (g) & $\begin{array}{l}\text { Fermented } \\
\text { flour (g) }\end{array}$ \\
\hline QN 1 & - & 25.00 & 75.00 \\
\hline QN 2 & 25.00 & 25.00 & 50.00 \\
\hline QN 3 & 37.50 & 25.00 & 37.50 \\
\hline QN 4 & 50.00 & 25.00 & 25.00 \\
\hline TCN & 75.00 & 25.00 & - \\
\hline
\end{tabular}

Table.2 Ingredients used in preparation of chekkalu with fermented quinoa flour

\begin{tabular}{|c|c|c|}
\hline Combinations & Rice flour (g) & Fermented quinoa flour (g) \\
\hline TC 1 & - & 100.00 \\
\hline TC 2 & 25.00 & 75.00 \\
\hline TC 3 & 50.00 & 50.00 \\
\hline TC 4 & 75.00 & 251.00 \\
\hline TCC & 100.00 & - \\
\hline
\end{tabular}


Fig.1 Mean sensory scores of namakpara incorporated with fermented quinoa flour

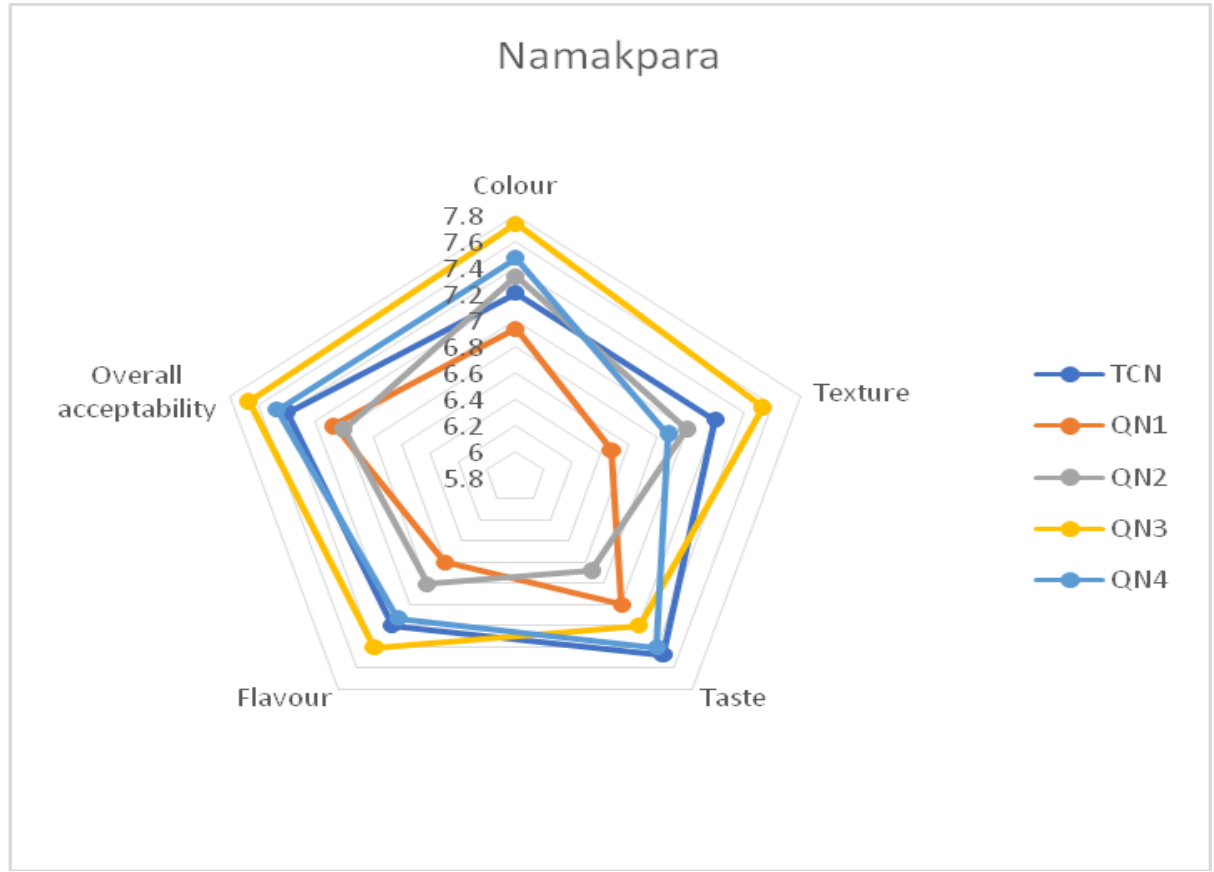

TCN (Control) - Namakpara prepared with wheat flour and maidha (75:25)

QN1 - Namakpara prepared with maidha and fermented quinoa flour (25:75).

QN2 - Namakpara prepared with wheat flour, maidha and fermented quinoa flour (25:25:50)

QN3 - Namakpara prepared with wheat flour, maidha and fermented quinoa flour (37.5:25:37.5)

QN4 - Namakpara prepared with wheat flour, maidha and fermented quinoa flour (50:25:25)

Fig.2 Box and whisker plots displaying median, inter quartile range (box) and range (whiskers) of overall acceptability of fermented quinoa incorporated namakpara

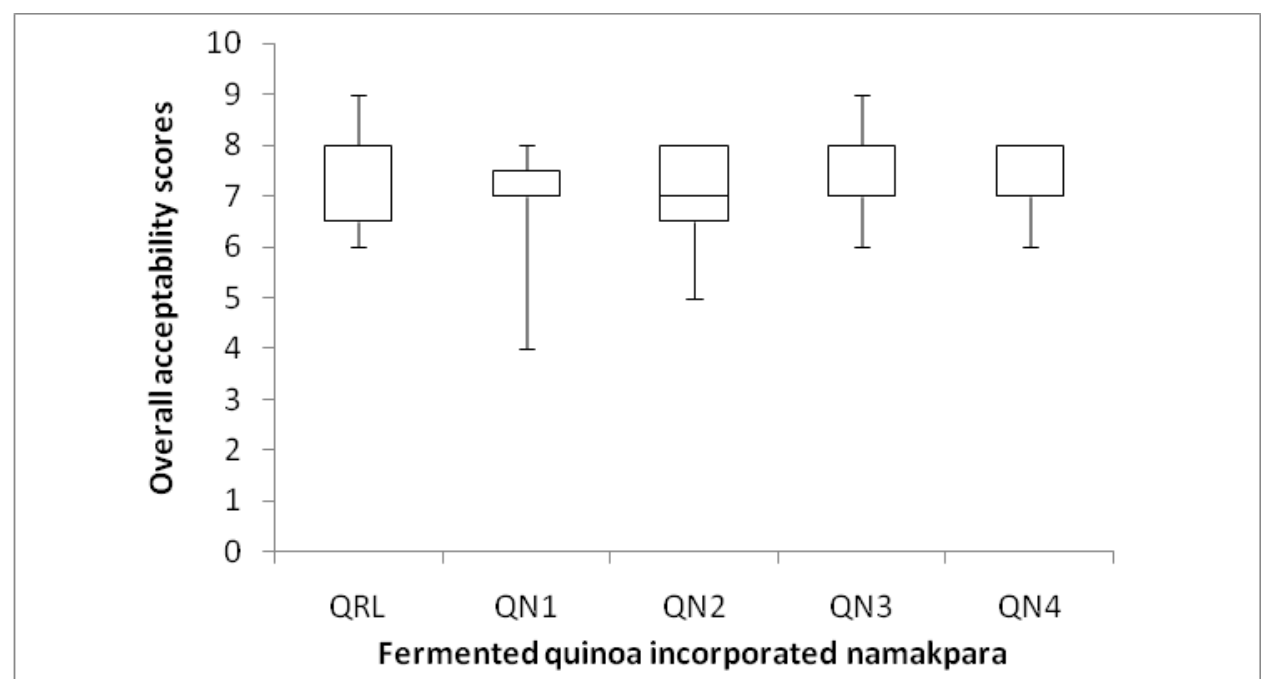

TCN (Control) - Namakpara prepared with wheat flour and maidha (75:25)

QN1 - Namakpara prepared with maidha and fermented quinoa flour (25:75).

QN2 - Namakpara prepared with wheat flour, maidha and fermented quinoa flour (25:25:50)

QN3 - Namakpara prepared with wheat flour, maidha and fermented quinoa flour (37.5:25:37.5)

QN4 - Namakpara prepared with wheat flour, maidha and fermented quinoa flour (50:25:25) 
Fig.3 Mean sensory scores of chekkalu incorporated with fermented quinoa flour

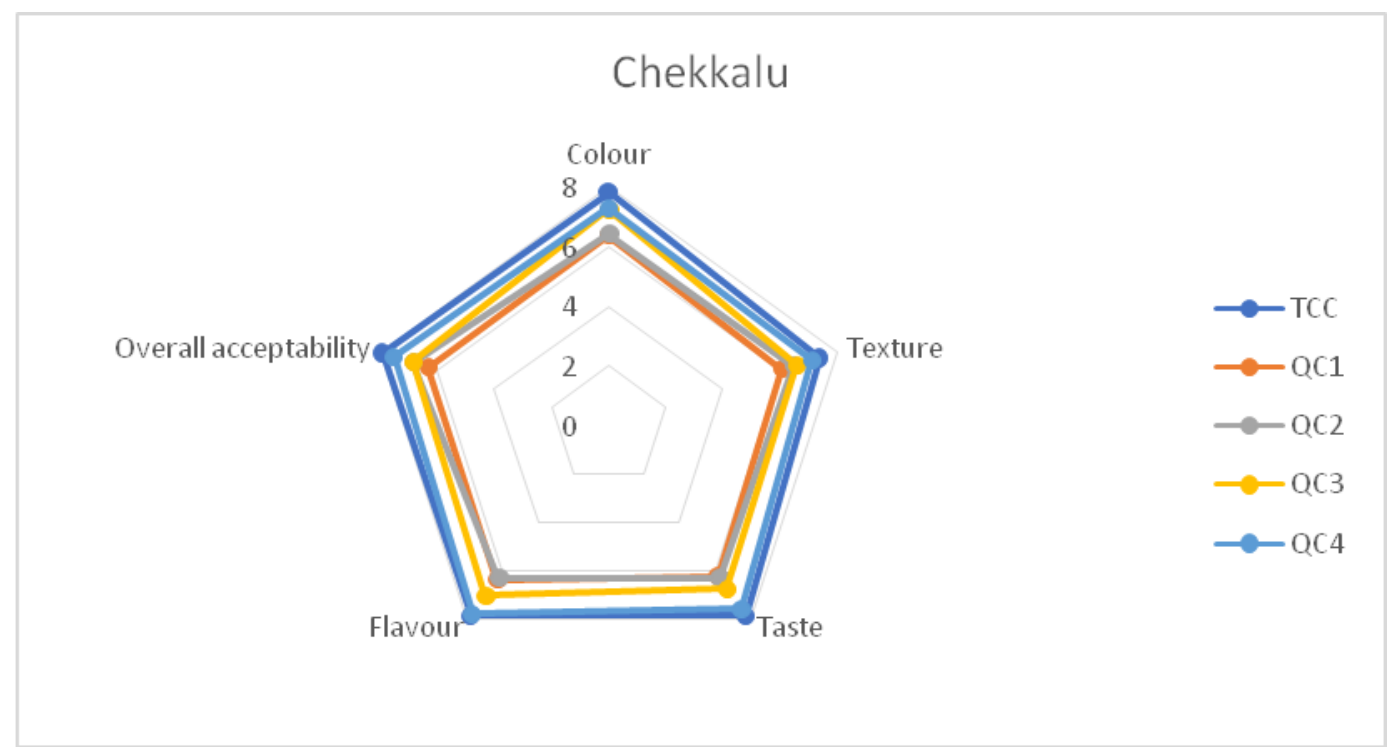

TCC (Control) - Chekkalu prepared with rice flour only

QC1 - Chekkalu prepared with fermented quinoa flour only

QC2 - Chekkalu prepared with rice flour and fermented quinoa flour (25:75)

QC3 - Chekkalu prepared with rice flour and fermented quinoa flour (50:50)

QC4 - Chekkalu prepared with rice flour and fermented quinoa flour (75:25)

Fig.4 Box and whisker plots displaying median, inter quartile range (box) and range (whiskers) of overall acceptability of fermented quinoa incorporated chekkalu

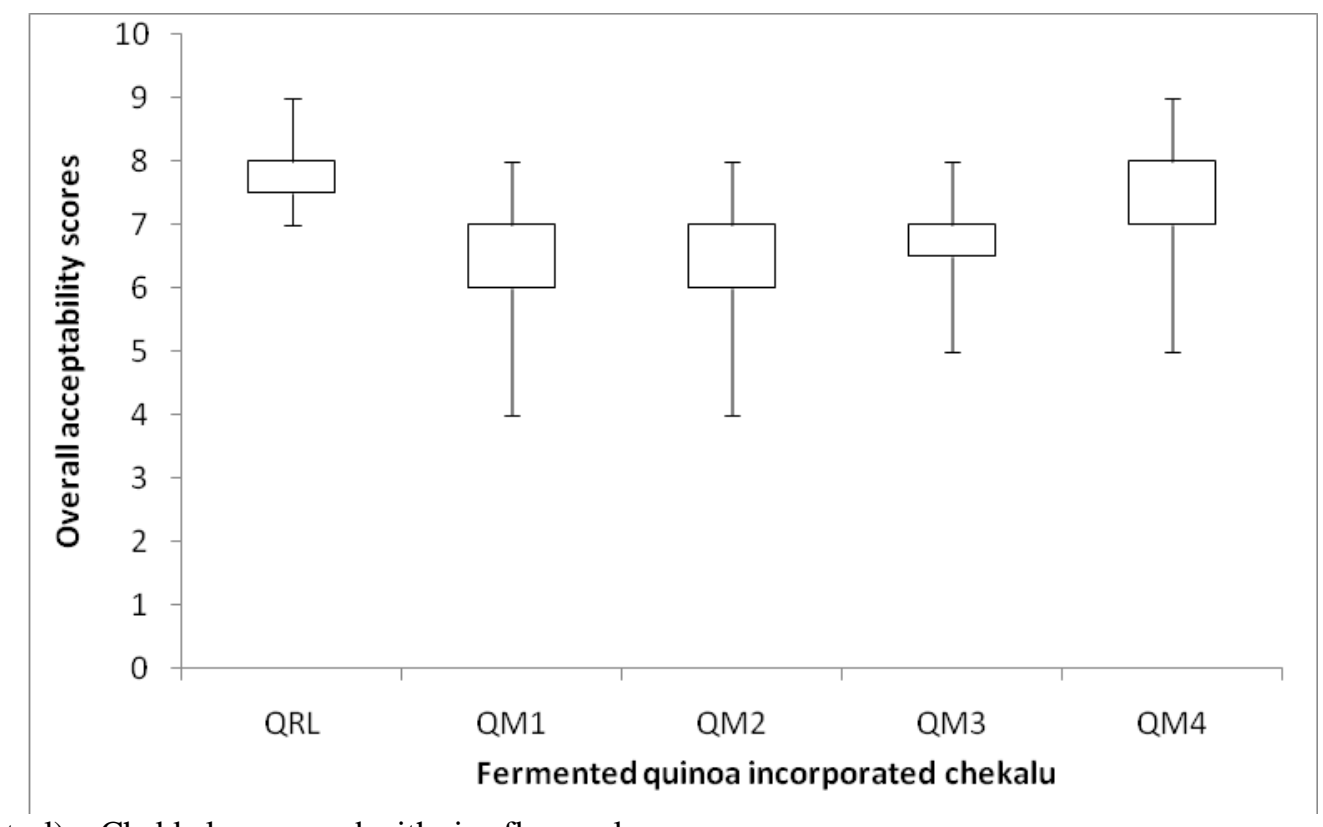

TCC (Control) - Chekkalu prepared with rice flour only

QC1 - Chekkalu prepared with fermented quinoa flour only

QC2 - Chekkalu prepared with rice flour and fermented quinoa flour (25:75)

QC3 - Chekkalu prepared with rice flour and fermented quinoa flour (50:50)

QC4 - Chekkalu prepared with rice flour and fermented quinoa flour (75:25) 


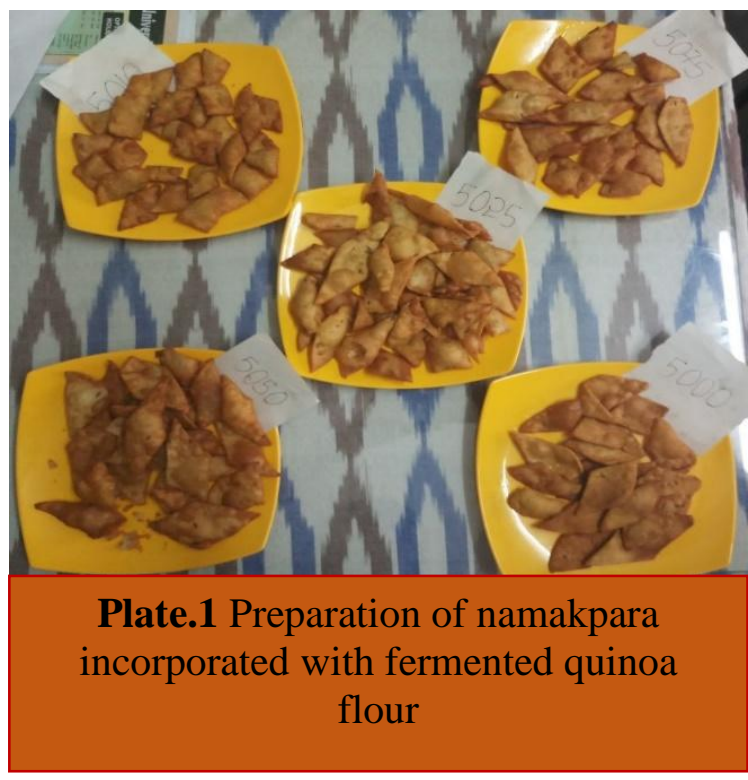

\section{Sensory evaluation of chekkalu incorporated with fermented quinoa flour}

Mean sensory scores of chekkalu was stated in Figure 3. Means sensory scores of chekkalu for colour, TCC $(7.80 \pm 0.22)$ was given highest mean sensory. Score than incorporated chekkalu with fermented quinoa flour. QC1 (7.80 \pm 0.22$)$ had lowest mean sensory score for colour. Acceptability of colour was decreased by increasing the incorporation of fermented quinoa flour to the chekkalu from QC1 to QC4. Results showed that there was significant difference $(p \leq 0.05)$ between TCC and chekkalu incorporated with fermented quinoa flour, and there was no significant difference $(\mathrm{p} \leq 0.05)$ between $\mathrm{QC} 1$ and QC2 and between QC3 and QC4.

Acceptability of chekkalu for texture mean sensory scores was decreased from QC1 to QC4 by increasing the incorporation of fermented quinoa flour. Control (7.40 \pm 0.29$)$ had highest score than chekkalu incorporated with fermented quinoa flour, and QC1 (6.07 \pm 0.27$)$ had lowest score. Mean sensory scores of chekkalu were raged from 7.40 \pm 0.29 to $6.07 \pm 0.27$. Results showed that there was significant difference $(\mathrm{p} \leq 0.05)$ between TCC

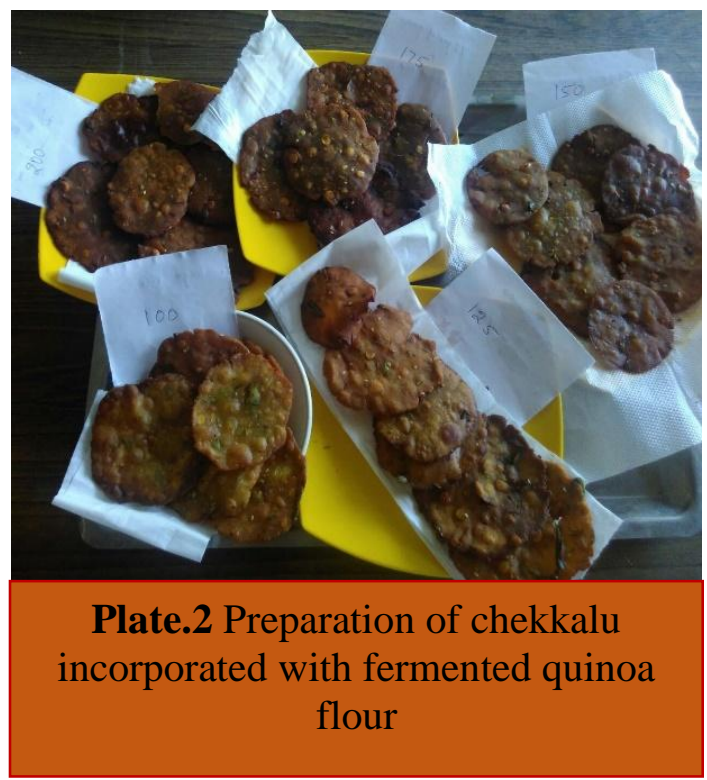

and chekkalu incorporated with fermented quinoa flour.

Highest mean sensory scores of chekkalu for taste $(7.80 \pm 0.24)$ and flavour $(7.80 \pm 0.22)$ were given to TCC than incorporated chekkalu with fermented quinoa flour. Within the fermented quinoa incorporated chekkalu QC4 got highest scores in the taste (7.53 \pm 0.26 ) and flavour (7.73 \pm 0.20$)$. Based on results taste and flavour of chekkalu was decreased by increasing the incorporation of fermented quinoa flour to the chekkalu. The results showed that there was significant difference $(\mathrm{p} \leq 0.05)$ between TCC and incorporated chekkalu with fermented quinoa flour.

Overall acceptability of incorporated chekkalu was decreased from 7.93 \pm 0.26 (TCC) to $6.33 \pm 0.29$ (QC1). Chekkalu prepared with control (TCC) $(7.93 \pm 0.18)$ scored highest for overall acceptability. In the experimental chekkalu with fermented quinoa flour QC4 (7.53 \pm 0.26) had maximum score as compared with QC2 $(6.87 \pm 0.22)$, QC3 $(6.87 \pm 0.22)$ and $\mathrm{QC} 1(6.33 \pm 0.29)$ for overall acceptability. Results showed that there was no significant difference $(\mathrm{p} \leq 0.05)$ between 
QC2 and QC3. Compared to TCC and chekkalu incorporated with fermented quinoa flour there was significant difference $(p \leq 0.05)$ between them.

To select final best acceptable combination of chekkalu the actual scores of overall acceptability given by 15 panel members were taken and box-plot diagram was drawn. Boxplot descriptive statistics are presented in Figure.4. The box plot diagram clearly shows that the median (8) and maximum (9) values of overall acceptability of control sample was equal to the QC4. And even minimum (7) value of overall acceptability was highest for control.

Quinoa is excellent nutritious grain but digestibility was low because of antinutrients. Traditional food processing technique like fermentation was used to improve the digestibility, nutrient content and enhance the flavour of products their by decreasing the antinutritional factors. Present study revealed that acceptability of snack items such as namakpara and chekkalu were organoleptically like moderately.

\section{Acknowledgement}

The authors thank Vice Chancellor of Professor Jayashankar Telangana Sate Agricultural University and Dean (i/c), Faculty of Home Science, PJTSAU, Rajendranagar, Hyderabad for their encouragement to carry out this research work.

\section{References}

Carciochi, M., Alessandro, L and Vandendriessche, $\mathrm{P}$ and Chollet, $\mathrm{S}$. 2016. Effect of Germination and Fermentation Process on the Antioxidant Compounds of Quinoa Seeds. Plant Foods Human Nutrition. 71(4): 361-367.

Corsetti, A and Settanni, L. 2007. Lactobacilli in sourdough fermentation. Food Research International. 40(5): 539-558.

Elgeti, D., Sebastian, D., Nordlohne, Föste, M., Besl, M., Martin, H., Linden, Heinz, V., Jekle, $\mathrm{M}$ and Becker, T. 2014. Volume and texture improvement of gluten-free bread using quinoa white flour. Journal of Cereal Science. 59 (1): 41- 47.

Kockova, M., Dilongov, M., Hybenova, E and Valik, L.U. 2013. Evaluation of cereals and pseudocereals suitability for the development of new probiotic foods. Journal of Chemistry. 1-8. http://dx.doi. org/10.1155/2013/414303.

Meilgaard, M, Civile, G. Vand Carr, B.T. 1999. Sensory Evaluation Techniques. 3rd Ed. CRC press, Boca Raton.

Snedecor, G.W and Cochran, W.G. 1983. Statistical Methods, Oxford and IBH publishing S company, New Delhi.

\section{How to cite this article:}

Prathyusha, P., B. Anila Kumari, K. Uma Maheswari, K.B. Suneetha Devi and Jessie Suneetha, W. 2018. Development of Traditional Snack Items with Fermented Quinoa. Int.J.Curr.Microbiol.App.Sci. 7(12): 3555-3561. doi: https://doi.org/10.20546/ijcmas.2018.712.402 